\title{
Final architecture diploma projects in the analysis of the UPC buildings energy performance
}

\author{
M. Bosch ${ }^{1}$, I. R. Cantalapiedra ${ }^{2}$, F. López ${ }^{3} \&$ G. Ruiz ${ }^{3}$ \\ ${ }^{1}$ Department of Architectural Technology II (EPSEB), \\ Technical University of Catalonia (UPC), Barcelona, Spain \\ ${ }^{2}$ Department of Applied Physics (EPSEB), \\ Technical University of Catalonia (UPC), Barcelona, Spain \\ ${ }^{3}$ The Interdisciplinary Centre for Technology, Innovation and Education \\ for Sustainability, Technical University of Catalonia (UPC), Barcelona, \\ Spain
}

\begin{abstract}
Education is the base for achieving sustainable development. With the purpose of introducing sustainable challenges in terms of climate change, water and energy consumption, the Technical University of Catalonia (UPC) has promoted the culture of energy efficiency in new generations of professionals that will work in the field of building construction. A group of 29 students taking the final official Diploma in Architecture were involved in a project of analysis of energy performance of UPC buildings in order to identify and implement cost-effective ways of promoting a greater environmental responsibility. The development of works focused the attention on introducing energy audits in existing university buildings, analysing the following aspects: surveying construction drawings, building characteristics, energy consumption, and use of natural lighting, energysaving lighting controls, water consumption, and high-efficiency HVAC systems. The ultimate goal was to draft a proposal with greater respect for the environment, and for corrective measures aimed at reducing the cities environmental impact.

This paper has the objective of publicising the results, from an academic standpoint, of a specific action carried out within the framework of the Energy Efficiency Plan (UPC, * 2002) that is now being implemented and that will allow the existing commitment to greening the university studies in Technical Architecture School to be strengthened. The first stage was performed through the energy audit of 24 UPC buildings, and, in view of the good results obtained, the second stage has now been started through other public office, school and sport buildings.
\end{abstract}

Keywords: curriculum greening, energy efficiency, interdisciplinary, public building performances, energy policies, power audits. 


\section{Introduction}

Sustainable development is an increasingly relevant goal in today's society, which should involve considerable change in our behaviors. A sustainable society can only be constructed through example, and through specific activities. The European Union (EU) Directive of building energy performance of buildings [1] could play a very important role in the future increase in energy efficiency. In many countries, current building codes have relatively low requirements for energy efficiency and renewable energy, which leads to a higher energy consumption than what is cost-effective. Because most houses are built according to these low standards, the users are laden with these unnecessarily high costs. New, stronger building codes that are enforced, can correct this problem, to the benefit of the users, the constructors and the environment. The new professionals in building construction need to know what are the today's European standards requirements for energy efficiency and how to evaluate and modify the actual park of buildings.

\section{Energy policies, public buildings and University}

Energy rating started just after the energy crisis. The concern of the industrialized countries about the high energy consumption of the building sector initiated actions and programs aiming to rationalize the energy consumption of dwellings.

In the same way as some other European countries (UK, Denmark, Germany, Netherlands, and Ireland for example) in Spain the effort of the governmental politics has been focused in the transposition of the energy efficiency of buildings directive.

The energy efficiency certificate is designed to evaluate the buildings in two stages. A first certificate is awarded in the design phase and a final one is provided to the finished building.

In Catalonia specifically, recent policies integrated in the decree of ecoficiency of buildings have been implemented, in order to establish new requirements for new buildings and major renovations.

According to this perspective, the main purpose of this work is the analysis of the energy performance of UPC buildings in order to identify and implement cost-effective ways of promoting a greater environmental responsibility. The work is part of the framework of UPC policies [2] that, in 2003, launched a project for auditing the energy efficiency of the university buildings so as to establish a Resources Consumption Efficiency Plan (focused mainly on energy and water).

UPC's interest in developing an Energy Efficiency Plan for consumption of energy resources, with the aim of auditing the existing buildings and defining policy and objectives for energy savings and efficiency, was seen as an opportunity for establishing links between teaching, research and management of the University. Within this framework, the Environment Plan Office, with the collaboration of the Department of Architectural Technology II and the 
Department of Applied Physics, has created a line of projects with the name Resources Consumption Efficiency Plan (PECR) - Energy Audits as a strategy focusing on learning by students.

\subsection{The PECR plan}

The PECR has developed a practical and useful methodology for auditing the energy performance of UPC buildings and assessing their environmental quality. This goal has been pursued on the basis of yearly rounds involving groups of students who receive, over a six-month period, individual and group teaching that obliges them to do research and learn under the interdisciplinary guidance of a group of lecturers with specific knowledge.

Projects linked to the PECR arose in connection with the "Guide to Greening Final Projects" [3] purpose and with the proposal of the Environment Plan Office to carry out an energy audit of all UPC buildings to assess their energy performance and establish potential improvements, both in respect of energy efficiency and consumption of resources, and to allow reduction of their environmental impact (Fig. 1, 2).

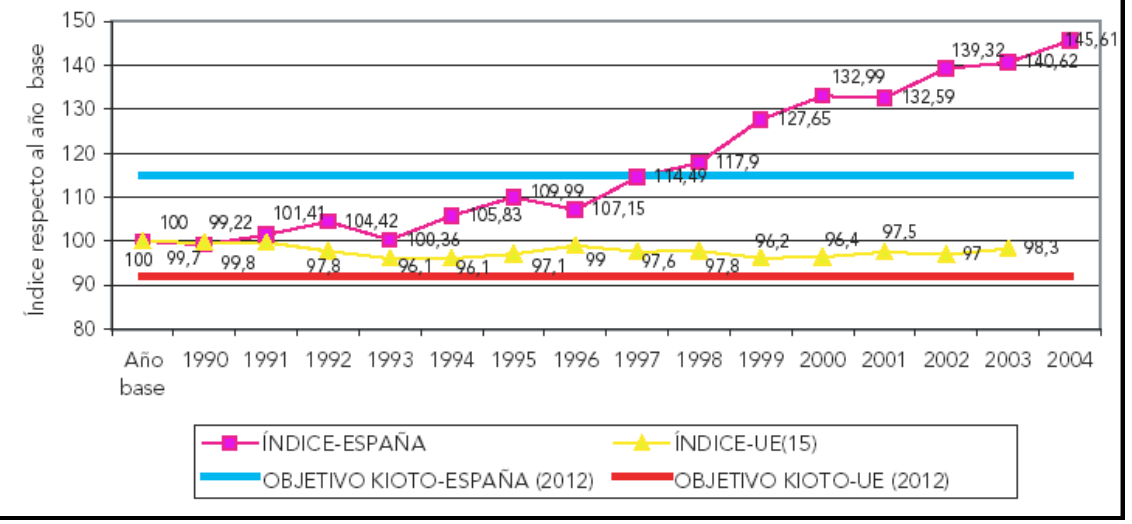

Figure 1: $\quad \mathrm{CO}_{2}$ emissions in $\mathrm{UE}$ and Spain.

\subsection{Methodology}

The development of the project planning for 6 months in duration, involved 29 students of the Technical Architecture School of Barcelona (EPSEB), 3 lecturers and various staff members from the Environmental and Maintenance Offices and other units. It included a weekly seminar day in order to discuss all the concepts that arose, and to share experiences. In conclusion, it was an enriching experience for the students.

Each student was expected to do their own work, but they were also encouraged to co-operate and share their experience, with the aim of ensuring the consistently high quality of all the work done. 


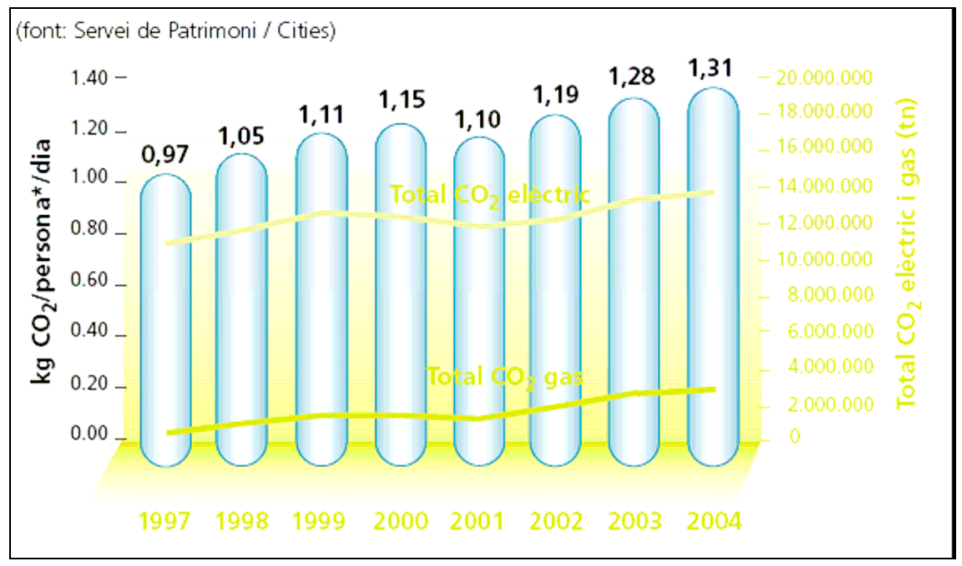

Figure 2: Daily consumption of energy per head, and $\mathrm{CO}_{2}$ emissions in UPC.

Once the programme was established, students were provided with tools and physical surroundings for their work adapting the different projects to the index or programme (Fig. 3) established in advance consisting of:

- Summary of general characteristics, with measurement data, a use specification sheet and architectural information on the envelope, the structure and interiors.

- Study of energy resources: electricity, gas, water, and other fuels.

- Analysis of systems: lighting, air conditioning, energy and outfitting, and water pipes, providing plans and sets of data sheets compiling all the information.

- Monitoring of energy consumption

- Data analysis and study of the energy efficiency of the building.

- Proposals for actions to be taken.

All data gathering, working methodology and analysis of the data obtained were carried out in accordance with models and experiences provided by the tutors and experts consulted during the course.

\section{Outcomes, results and benefits}

Any initiative that it tries to define improvement criteria, saving or power efficiency, it needs to define the scene to begin with. In the case of UPC experience it was necessary to make a previous diagnosis and to define the possible lines of "general" performances:

- Substitution of energy resources

- Incorporation of green electricity.

- Specific actuations on the buildings and

- Power audits, included on PECR Plan. 


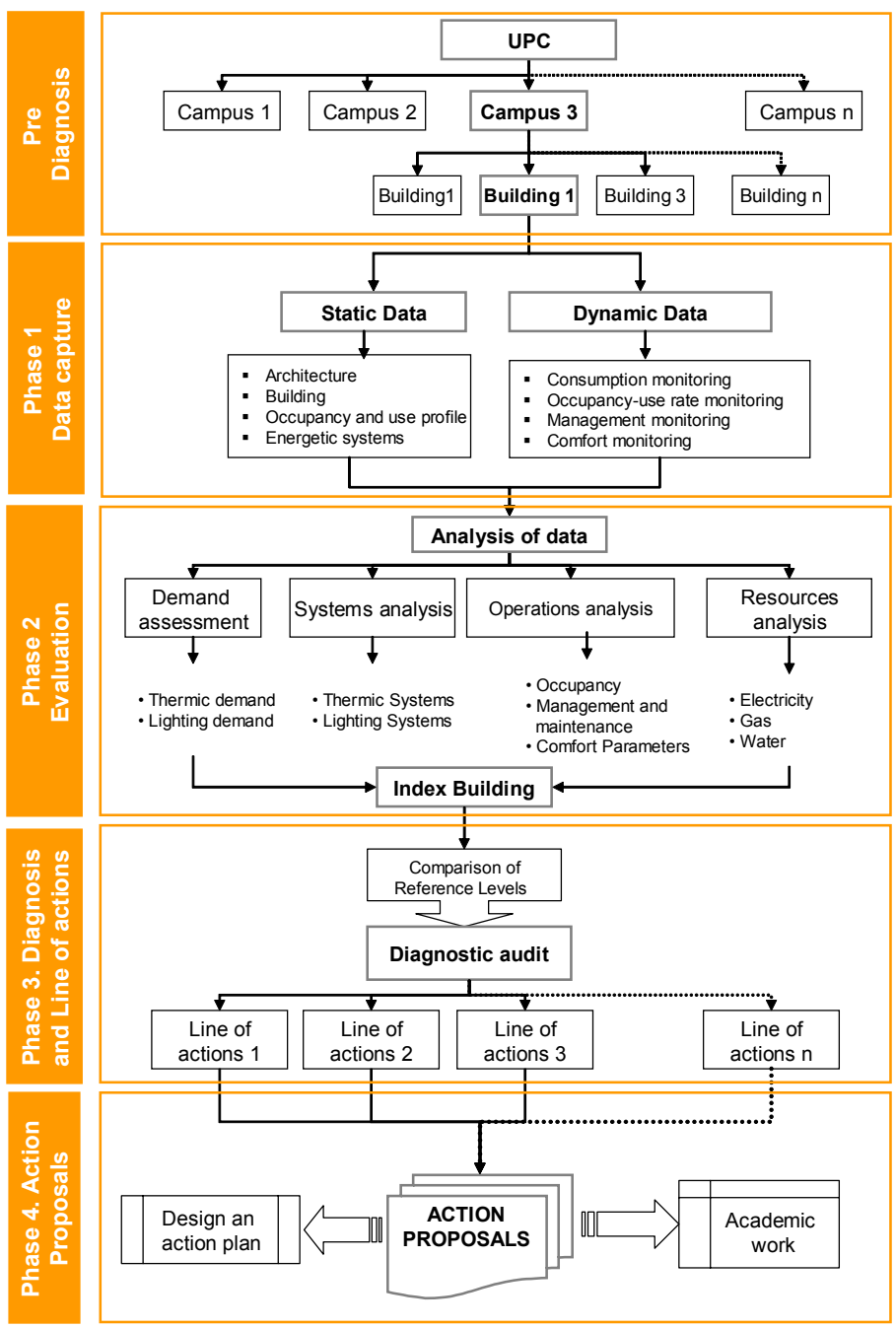

Figure 3: $\quad$ PECR Program.

At the end of all this process, we can define the lines of performance in which it is necessary to take part and the specific actions that must be developed. Different proposals are grouped in which we called "lines of performance", related with the methodology used during the data measurement and the evaluation. At the end, we defined:

- Actuations related with the building envelope: architectonic and constructive characteristics of the building, especially focused on the façades and roofs. The objective of this kind of proposals is to reduce the energy performance level. 
- Actuations on the energy resources systems: lighting, air conditioning, and others.

- Performances related to the management of the power resources: occupation of the buildings, uses and functions (timetables, periods, etc.).

Each one of the performances identified must be valued according technical, economics and logistic viabilities and it's necessary to provide the priorities framework in order to ensure that available resources will be invested the most effective and efficient way.

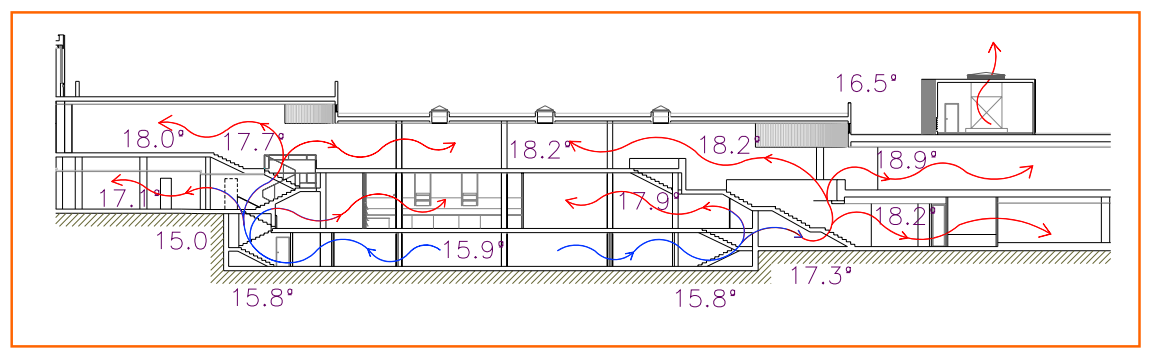

Figure 4: Barcelona Architecture University School, Coderch building.

\section{Conclusions}

The discussion of sustainability and its relationship with architecture often turns on an evaluation of the impact of the materials and energy consumed in the use of the buildings. But the must important impact that University activities can incorporate in the environmental is to generate new attitudes in the students, as part of their education.

Universities must redirect the teaching-learning process in order to become real change agents who are capable of making significant contributions by creating a new model for society. Responding to change is a fundamental part of a university's role in society. The United Nations Decade on Education for Sustainable Development (2005-2014) offers a great opportunity to consolidate and replicate this existing good practice across the international higher education community.

The development of this work has permitted to integrate, in a positive experience, the main working groups of the university: investigators, managers and professors. This confirms the need to define the objectives of the sustainability from an interdisciplinary perspective.

\section{References}

[1] Directive of building energy performance of buildings 2000/91/EC of the European Parliament and the Council of 16 December 2002. 
[2] Universitat Politècnica de Catalunya UPC. Second Environment Plan Projects (2004).

[3] Curriculum Greening in final theses and subjects. Second Environmental Plan. www.upc.edu/cities.

[4] Environmental criteria in buildings and on campus. www.upc.es/mediambient/vidauniversitaria/edificis.html. 